\title{
Autosomal dominant optic atrophy and peripheral neuropathy
}

INSERM

\section{Source}

INSERM. (1999). Orphanet: an online rare disease and orphan drug data base. Autosomal dominant optic atrophy and peripheral neuropathy. ORPHA:250932

Autosomal dominant optic atrophy and peripheral neuropathy (ADOAPN) is a form of autosomal dominant optic atrophy (ADOA, see this term), characterized by progressive and isolated visual loss in the first decade of life, decreased reflexes in the lower limbs and a mild cerebellar stance. 